\title{
Proposal for a National Blueprint Framework to Monitor Progress on Water-Related Sustainable Development Goals in Europe
}

\author{
B. Essex ${ }^{1,2}$. S. H. A. Koop ${ }^{1,2} \cdot$ C. J. Van Leeuwen ${ }^{1,2}$
}

Received: 9 August 2019 / Accepted: 16 November 2019 / Published online: 3 December 2019

(c) The Author(s) 2019

\begin{abstract}
The 17 Sustainable Development Goals (SDGs) underpinned by 169 targets presents national governments with huge challenges for implementation. We developed a proposal for a National Blueprint Framework (NBF) with 24 water-related indicators, centered on SDG 6 (clean water and sanitation for all), each with a specific target. We applied the NBF to 28 EU Member States (EU-28) and conclude that:

(1) The current SDG 6 indicators are useful for monitoring progress toward water-related targets but their usefulness can be improved by focusing more on their practical implementation.

(2) The extension of SDG 6 with complementary indicators (e.g. for the circular economy of water) and quantitative policy targets is urgently needed. This will benefit the communication process and progress at the science-policy interface.

(3) SDG indicators can be improved in a SMART (specific, measurable, achievable, relevant, and time-bound) manner and by setting clear policy targets for each indicator, allowing for measuring distance-to-targets. This allows country-tocountry comparison and learning, and accelerates the SDG implementation process.

(4) We propose 24 water-related indicators centered on SDG 6, with complementary indicators including quantitative policy targets. The approach is doable, easily scalable, and flexibly deployable by collecting information for the EU-28.

(5) Main gaps in the EU-28 are observed for water quality, wastewater treatment, nutrient, and energy recovery, as well as climate adaptation to extreme weather events (heat, droughts, and floods).

(6) The framework was less successful for non-OECD countries due to lack of data and EU-centric targets for each indicator. This needs further research.
\end{abstract}

Keywords Sustainable development goals $\cdot$ Water management $\cdot$ Circular economy $\cdot$ Indicators $\cdot$ Implementation

\begin{tabular}{lll}
\multicolumn{2}{l}{ Abbreviations } & IBNET \\
BCI & Blue City Index \\
CBF & City Blueprint Framework & IWRM \\
EU & European Union & JMP
\end{tabular}

EU-28 28 Member States of the European Union

Supplementary information The online version of this article (https:// doi.org/10.1007/s00267-019-01231-1) contains supplementary material, which is available to authorized users.

C. J. Van Leeuwen

kees.van.leeuwen@kwrwater.nl

1 KWR Water Research Institute, Groningenhaven 7, 3433 PE Nieuwegein, the Netherlands

2 Copernicus Institute of Sustainable Development, Utrecht University, Princetonlaan 8a, 3508 TC Utrecht, the Netherlands international benchmarking network for water and sanitation utilities

integrated water resources management WHO/UNICEF Joint Monitoring Program for Water Supply, Sanitation and Hygiene

NBF National Blueprint Framework

NPI National Blueprint Index

MDGs Millennium Development Goals

OECD Organization for Economic Co-operation and Development

SDG UN Sustainable Development Goal

SDG 6 SDG to ensure availability and sustainable management of water and sanitation for all

SW solid waste

SMART acronym, giving criteria to guide in the setting of objectives. The letters $\mathrm{S}$ and $\mathrm{M}$ generally mean specific and measurable. The remaining 
letters refer to achievable (or attainable), relevant, and time-bound

$\begin{array}{ll}\text { TWAP } & \text { Transboundary Water Assessment Program } \\ \text { UN } & \text { United Nations } \\ \text { UNDP } & \text { United Nations Development Program } \\ \text { UNEP } & \text { United Nations Environment Program } \\ \text { WFD } & \text { Water Framework Directive } \\ \text { WHO } & \text { World Health Organization } \\ \text { WPI } & \text { World Poverty Index } \\ \text { WWT } & \text { wastewater treatment }\end{array}$

\section{Introduction}

\section{Water Challenges and Sustainable Development}

Water is crucial for human survival. It has been estimated that a minimum of 7.5 liters of water per person per day is required in the home for drinking, preparing food, and personal hygiene, the most basic requirements for water; at least 50 liters per person per day is needed to ensure all personal hygiene, food hygiene, domestic cleaning, and laundry needs (Hunter et al. 2010; Howard Bartram 2003). This however, does not include the amount of water used in agriculture, industry and which is required to maintain the Earth's ecosystems. The global population is increasing from the current 7.7 billion to reach 8.5 billion by 2050 , with over half of the population concentrated in less economically developed nations (United Nations 2015a). As these nations develop, the standard of living will increase and so with it the consumption of more water. Drinking water consumption in cities varies a lot. For instance, in Amsterdam and Copenhagen, the consumption is about 138 liters/person/day, whereas it is 622 liters/person/day in Bologna (Gawlik et al. 2017). Furthermore, in some areas overexploitation of groundwater may result in land subsidence and further increase the risks of flooding (Koop and Van Leeuwen 2017; Rahmasary et al. 2019).

Public water use is not the major freshwater use. In Europe, $44 \%$ of extracted water is used for agriculture and $40 \%$ for industry and energy production (EEA 2018). Detailed information about water withdrawal per sector is provided by the FAO (2016). Indirect water use via food consumption exceeds 3000 liters daily for most European Union (EU) citizens (Gawlik et al. 2017), meaning that actual agricultural water consumption exceeds $90 \%$ of total consumption (Hoekstra et al. 2012; Hoekstra 2014). With the increase in global population, the demand for food is expected to increase, added to this, the global trend toward a more meat-based diet will result in higher water consumption (Gawlik et al. 2017; Hoekstra 2014) and energy requirements per joule of energy in the food. To meet the increased food demand, land use is currently changing, from natural grassland and forests to agricultural land (Lambin and Meyfroidt 2011). The intensification of agricultural practices may increase with the use of agrochemicals to provide higher food yields. Loss of natural land reduces the area of natural water filtration and increases surface run off, increasing flood risk particularly in densely populated deltas and along the rivers and coasts. Use of chemicals in agriculture is a key contributor to water pollution (FAO 2018), the extensive amount of irrigation, and monocultures also lead to land degradation. Agriculture has direct environmental impacts on water quality, as well as indirect effects due to the increase in energy requirements. Both groundwater pumping for irrigation and increased agrochemical use result in increased water use and energy use per hectare (Rasul 2016), more industrial waste, as well as groundwater depletion (De Graaf et al. 2019).

Water is an important resource, with increasing demand but is also a critical requirement to the development of multiple sectors discussed above. With the end of the Millennium Development Goals (MDGs) in 2015 (United Nations 2015b), the Sustainable Development Goals (SDGs) were developed to continue the international agreement to sustainable development, this is known as the 2030 Agenda for Sustainable Development (United Nations 2015c). As water is so relevant, it was included as an individual Sustainable Development Goal (SDG) for Agenda 2030. Implementation matters (United Nations 2018).

\section{A Critical Reflection on the SDGs}

\section{History}

The frequently cited beginning of the current sustainable development [rhetoric] is "Our common future" (Brundtland 1987). This narrative required economic development to occur as part of sustainable development (De Vries 2012; Robinson 2004). The Brundtland report also stressed the necessity of international cooperation for sustainable development. This conclusion increased awareness of the importance of sustainable development and led to further research and discussion. This gave rise to the MDGs for 2000-2015. The MDGs are focused on the development of the global south and have an anthropogenic focus of development. Whilst the MDGs had some large achievements (United Nations 2015b) the economic achievements were greater than the environmental goals (Georgeson and Maslin 2018). With the end of the MDGs in 2015, the SDGs were developed to continue the international agreement to sustainable development, this is known as the 2030 Agenda for Sustainable Development. Here the perception of sustainability has developed to include the requirements of environmental sustainability to achieving social and 
Fig. 1 The water-centric 17 Sustainable Development Goals for each sector (United Nations 2015c; Makarigakis and Jimenez-Cisneros 2019; with permission)

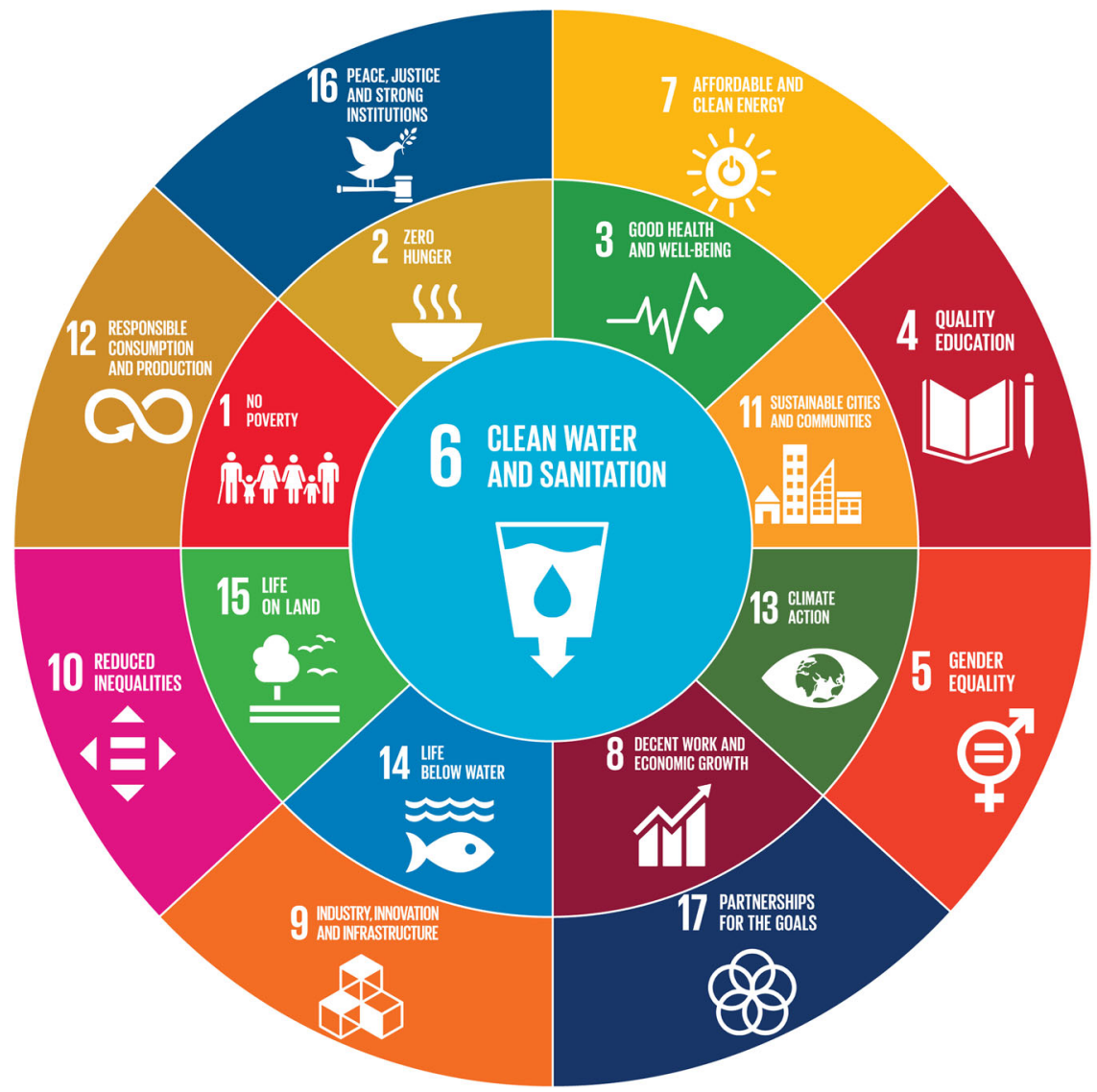

economic sustainability. The approach of the SDGs is people, planet and prosperity to include economic growth, environmental sustainability and social inclusion (United Nations 2015c).

Adopted in 2015, the SDGs form an internationally recognized set of goals and targets which aim to promote development in the economy, environment and society. There are a total of 17 goals (Fig. 1) containing 169 targets with a focus on people, planet, prosperity, peace, and partnerships. The SDGs aim for a larger, holistic approach than the MDGs. Although the SDGs have a higher number of targets, the number of indicators per target is less, with only 1.4 indicator per target compared with the 2.67 indicators per targets seen in the MDGs (Georgeson and Maslin 2018). In some respects, with so many targets, more indicators per target would require a large amount of monitoring.

A key learning point from the MDGs was that what gets measured, gets managed (Barnett 2015). The design of the indicators and what they measure affects what becomes developed and people aim to achieve higher results from the indicator monitoring (Bhaduri et al. 2016; Georgeson and Maslin 2018; Reidhead et al. 2016). Therefore, the lack of indicators may mean that the end goal targets are not met, and consequently more target-specific indicators may be beneficial. The indicators show progress to achieving the targets and thus the final goals, however in some cases the indicators are not sufficient to discern whether the target has been met (Weststrate et al. 2019). Target 6.1 for SDG 6 (water) is "universal and equitable access to safe and affordable drinking water for all" (Table 1). Therefore to be able to measure if this has been achieved, the data should be disaggregated and collected by age, gender, and income (Guppy et al. 2019). Many of the targets are nonnumerical and therefore even though indicator data is collected the end goal remains vague (Dickens et al. 2019) and the data can only be used as a comparative to other countries.

\section{Trade-offs and synergies}

Taking the indicators as individual measurements to work toward may have unexpected consequences. If a linear management approach is taken, progression toward one indicator, target or goal of the SDGs may result in a cancellation effect whereby progression toward another goal is then limited. Alternatively the development toward one indicator could result in a situation where one indicator then depends on the progress of another in order for development to occur (Scherer et al. 2018). These interlinkages occur due to feedback loops between the goals (Allen et al. 2018) and 
Table 1 The targets and associated indicators for SDG 6 of the SDGs (United Nations 2015c)

Targets
6.1
By 2030, achieve universal and equitable access to safe and affordable
drinking water for all
6.2

6.2

By 2030, achieve access to adequate and equitable sanitation and hygiene for all and end open defecation, paying special attention to the needs of women and girls and those in vulnerable situations

6.3

By 2030 , improve water quality by reducing pollution, eliminating dumping and minimizing release of hazardous chemicals and materials, halving the proportion of untreated wastewater and substantially increasing recycling and safe reuse globally

6.4

By 2030, substantially increase water-use efficiency across all sectors and ensure sustainable withdrawals and supply of freshwater to address water scarcity and substantially reduce the number of people suffering from water scarcity

6.5

By 2030, implement integrated water resources management at all levels, including through transboundary cooperation as appropriate

\section{6}

By 2020, protect and restore water-related ecosystems, including mountains, forests, wetlands, rivers, aquifers, and lakes

6.A

By 2030, expand international cooperation and capacity-building support to developing countries in water- and sanitation-related activities and programs, including water harvesting, desalination, water efficiency, wastewater treatment, recycling, and reuse technologies

6.B

Support and strengthen the participation of local communities in improving water and sanitation management
Indicators

6.1 .1

Proportion of population using safely managed drinking water services

\section{2 .1}

Proportion of population using safely managed sanitation services, including a hand-washing facility with soap and water

\section{3 .1}

Proportion of wastewater safely treated

6.3.2

Proportion of bodies of water with good ambient water quality

\section{4 .1}

Change in water-use efficiency over time

6.4 .2

Level of water stress: freshwater withdrawal as a proportion of available freshwater resources

6.5 .1

Degree of integrated water resources management implementation $(0-100)$

6.5.2

Proportion of transboundary basin area with an operational arrangement for water cooperation

6.6 .1

Change in the extent of water-related ecosystems over time

\section{A.1}

Amount of water- and sanitation-related official development assistance that is part of a government-coordinated spending plan

\section{B.1}

Proportion of local administrative units with established and operational policies and procedures for participation of local communities in water and sanitation management in some cases due to indicators being used for more than one goal (Pradhan et al. 2017).

The feedback loops between the goals lead to synergies, where development in one goal is beneficial to another (UN-Water 2016), as well as trade-offs (where development in one goal negatively impacts another). The goals that contain the most synergies are the social development goals: Poverty, zero hunger, good health, education, and gender equality (SDGs 1-5). Those with the highest number of trade-offs are economic growth and the environment (SDGs 8, 9, 12, 15; Pradhan et al. 2017). These interactions occur due to the current reliance of economic growth on increasing levels of consumption at the detriment to the environment. Work needs to be done in these areas to allow economic growth to detach from consumption. Without this, meeting the global population's global needs and therefore meeting goals 1-3 will have a detrimental effect on the global use of water and land as well as increase the carbon emissions (Scherer et al. 2018) and lack of achievement of SDG 13,15, and 6. The main problem of meeting people's basic needs is that the level of consumption increases, however, progression toward a goal of responsible production and consumption (SDG 12) has the greatest trade-offs with meeting SDG 6 (Pradhan et al. 2017). These trade-offs must also be taken into consideration when creating policy to achieve the SDGs.

The separation of policy makers in different managerial departments often leads to policy becoming linear, with targets and actions for each indicator (Allen et al. 2018; Nilsson et al. 2016). To avoid this, an integrated approach is required to ensure that those actions that have synergies with other targets are implemented (Allen et al. 2018). This can often be hindered by the lack of technical capacity of skillsets of the policy makers. For this reason techniques are required to identify the goal synergies before policy is made, and frequent monitoring must occur to ensure that 
cancellation does not occur (Nilsson et al. 2016). The difference in national environment impacts the degree to which the synergies occur, and the impact that different actions have. For example in Nordic countries, biofuel does not have a negative impact on food production (Nilsson et al. 2016) and therefore could be used as an alternative energy source.

\section{The Implementation of the SDGs}

\section{SDGs and support for national water policies}

An important aspect to consider is whether the collection of indicator data is beneficial to the nation collecting it. Continuing with the example above, the "access for all to a water supply" can be compared with other countries, however, for the individual nation, it does not provide data on the underlying reason behind the amount of access. An example given is that Ghana lacks water access due to lack of supply, whereas Nepal lacks access to water due to the level of contamination (World Bank 2018). Understanding the background reason on a national level provides an indication for the required water management.

\section{SDG monitoring programs}

Both Eurostat and the United Nations Environment Program (UNEP) have current SDG monitoring strategies. However, they both differ from the proposed study. Eurostat focuses on indicator trends for measuring the amount of change toward achieving the SDGs. The use of trends requires historic and current data and whilst Eurostat has both long-term and short-term trend data, the lack of historic data is still limited for all indicators of SDG 6 (except for 6.1 and 6.2), preventing the calculation of an overall trend score. In addition to this, the use of trends means that the Eurostat monitoring cannot use new indicators for recently measured data. The display of the Eurostat monitoring focuses on the results of the targets for each goal. Alternatively to this, the monitoring carried out by UNEP is for seven areas of environmental interest with each area having a selection of appropriate targets taken from different goals. Whilst this does work to highlight the synergies between goals, none of the seven areas specifically focusses on the management of water resources.

The Organization for Economic Co-operation and Development (OECD) has a set of SDG monitoring indicators that focus on the progression toward achieving the goals (OECD 2017, 2019a). Where there is no global data available for an SDG indicator, the OECD has identified an alternative indicator, however, in total, the indicators chosen by the OECD only evaluate 57\% of the SDG targets (OECD 2017). Some of the missing indicators include those for water quality and transboundary water management amongst others meaning that SDG 6 is lacking coverage in these areas. The indicators are given as progression toward goals, where the target is either that given within an SDG target or it is the performance of the top $10 \%$ of OECD countries. Using the second target would mean that those countries in the top $10 \%$ would see no reason for further progression, even in situations where improvement could still occur.

\section{SDG 6 and integrated water resources management}

SDG 6 aims to address the increasing global problem of water scarcity with the aim to: Ensure availability and sustainable management of water and sanitation for all (United Nations 2015c). To enable this to happen eight targets have been agreed with nine associated indicators (Table 1).

Target 6.5 of SDG 6 is to implement Integrated Water Resources Management (IWRM) at all levels. IWRM is a policy making philosophy that aims to have a comprehensive and holistic approach to water management. However, what made IWRM popular was also part of its downfall; the broad scope, ambiguity of the concept and the lack of data made it difficult to create a holistic IWRM assessment framework for a national scale (Medema et al. 2008).

In order to assess the effectiveness of the IWRM and to provide feedback for decision makers, indicator frameworks are used. Many indicator frameworks focus on an individual problem such as the Water Stress Index and the Water Poverty Index (WPI). These indicators lack a holistic overview of the problem and in the case of WPI are complicated for policy makers to utilize (Petit 2016).

To decrease the complexity of IWRM indicators, some have chosen to focus on a specific geographic area such as the INBO Performance Indicators for African Basin Organizations or CAP-Net, a United Nations Development Program indicator for basin scale management.

Indicators on a city level include the City Blueprint Framework (CBF) which uses multiple performance orientated indices which report on different aspects of IWRM. The geometric average for each of the 25 indicators of the CBF forms the Blue City Index (BCI), which is available for more than 70 municipalities and regions in 40 different countries (Koop and Van Leeuwen 2015a, b). However, there is a lack of national level indexes that aim to give a holistic report on water management strategies.

In recent years IWRM has begun to lose its influence as an attractive management framework. There have been suggestions within the literature to move away from a onesize fits-all framework (Giordano and Shah 2014). This can be seen in the UNs' World Water Development Reports 
which in 2012 placed IWRM as a central focus of the report, in 2015 it was scarcely present (Petit 2016).

\section{Knowledge Gap and Research Questions}

Whilst the 17 individual SDGs are beneficial in that they together emphasize the extent to which sustainable development is interdisciplinary, they also result in isolating the different components of sustainable development. The further division of each goal into separate targets results in national managements strategies aiming for distinct targets within the goals rather than a cohesive development strategy. The problem of individualizing the goals is that many have conflicting interests which result in synergies and trade-offs between the ability to meet all the SDGs (Pradhan et al. 2017). The problem of this approach, which fails to highlight conflicting interests, is exemplified in water management. Although, water resources have their own target, SDG 6 focusses primarily on drinking water and sanitation, without appreciating the links between e.g. water, energy, agriculture, and health (Fig. 1).

Although there are theoretical approaches to managing water, often these are very challenging to achieve in practice (Savenije and Van der Zaag 2008). The governance actions required to meet the SDGs have been left to the individual nations. In fact, national governments conduct "only" voluntary national reviews. For many nations, this requires governance mechanisms to be strengthened (HLPW 2018) so that decisive actions can be taken (HLPW 2018) to reduce the risk of cherry-picking of the easiest goals to achieve. This uncoordinated approach may lead to international disputes and unanticipated side-effects.

There are many city-level indicators for sustainable living and water management (Hoekstra et al. 2018; European Commission 2015; Koop and Van Leeuwen 2015a; Siemens 2012), but alignment is required between national targets and the local performance. Globally, many countries lack consistent reporting strategies or the incentive to share data (Malik et al. 2015). This leaves many nations and international agencies uncertain about their progress toward the SDGs.

Many water-related indicators, whilst useful, do not show the scope of variables affecting water management. For example, the water scarcity index shows overuse of water, however, even if a country has water available, it may not be useable due to its poor quality-this is not shown with the water scarcity indicator. Conversely, with a more general indicator, there is a risk that the source of the development problem is lost (World Bank 2018). Therefore, there is a requirement for a water management index, which shows clear indicator results without over-simplifying the information on a national level. There is therefore, a need for a coordinated approach to water-management that incorporates indicators of multiple sectors for holistic SDG monitoring.

Based on the observed discrepancy between concepts such as IWRM that consider water as the principal unit of integration on the one hand, and SDGs and their specific targets on the other hand, the following research questions have been formulated: (1) What indicators can be used to create a water management framework for effective monitoring of progress in the EU-28? (2) What national indicators currently exist for water management assessment on a national level? (3) To what extent do these indicators align with the current SDG 6 targets and indicators? (4) Can a more suitable set of indicators be developed taking into account constraints of time and data availability? (5) To what extent does the proposed framework represent regional variability within European countries and non-EU countries?

\section{Development of a Framework of Water- related Indicators at National Level}

\section{Literature Review}

In determining what IWRM indicators are currently used at a national level a literature review was performed. A further in-depth assessment of the individual indicators used for the IWRM index was then carried out. This was done by entering each new indicator into a spreadsheet. The spreadsheet will count the number of times an indicator gets entered. Where indicators are essentially the same but are described differently, they would be grouped together. For example "water-related risk" from the sustainable city index (Batten 2016) and "exposure to floods and drought" from the TWAP-rivers indicators (UNEP-DHI and UNEP 2016) would be grouped together.

The assessment for the degree of indicator alignment with the SDG targets was carried out in two stages. A literature review was carried out to identify weaknesses and areas for improvement in the selected targets and indicators for the SDGs. This was done using Scopus with the search terms "SDG" AND water AND "goal 6" AND indicators, "SDG" AND water AND "goal 6" AND indicators, "SDG" AND "goal six" OR "goal 6", "SDG" AND water AND "goal 6" AND indicators AND review, "agenda 2030" AND water AND indicators for the years between 2015 and 2019. This yielded a cumulative total of 217 papers, of these those relevant for review were then selected. The time frame was chosen partly to limit the responses. Following this review, a correlation analysis was then carried out between IWRM indicators entered into the database devised to answer question one and SDG target and indicators. The Pearson correlation coefficient ( $r$ ) was used to assess the relationship between the IWRM indicators and the SDG indicators as well as the IWRM 
Fig. 2 Flow diagram of the indicator development
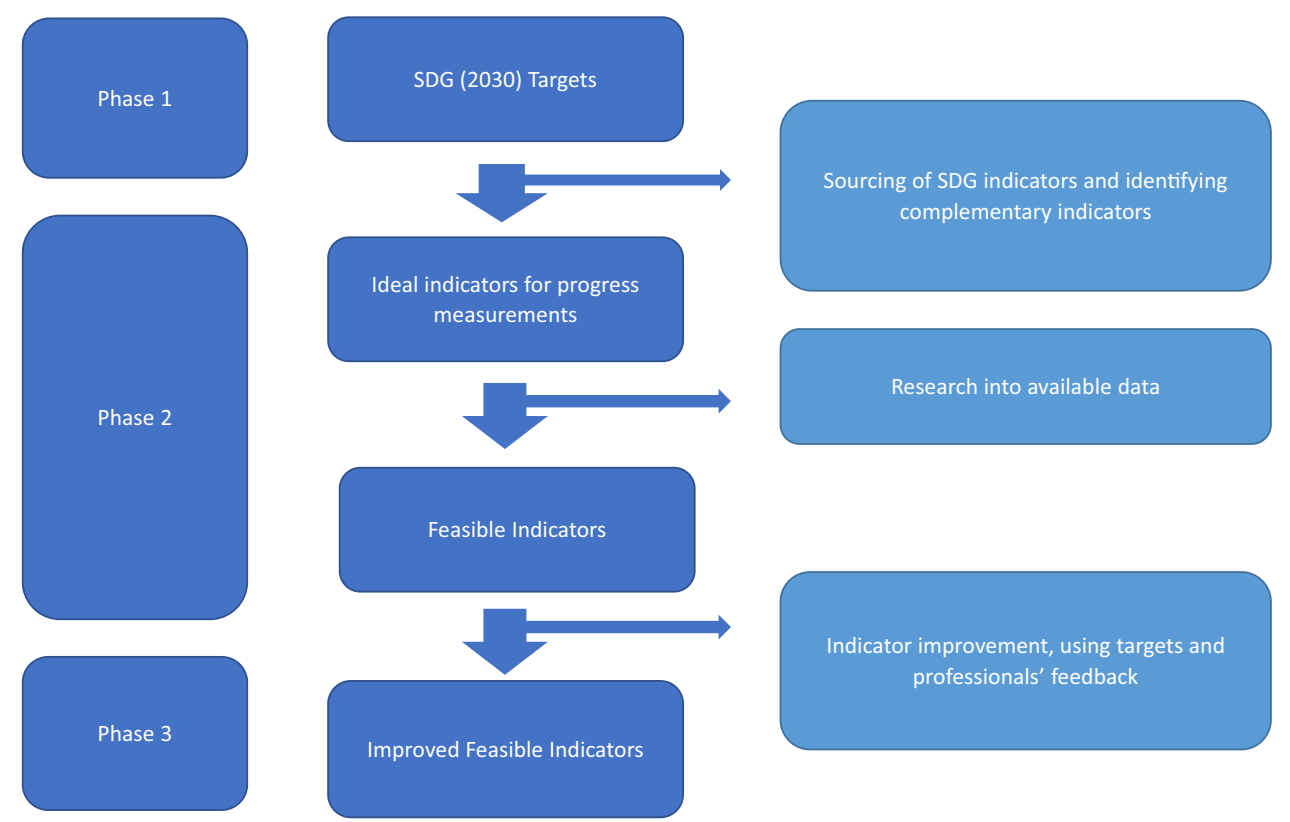

indicators and the SDG targets. The results were used to identify which indicators could be used for inclusion in the National Blueprint Framework (NBF).

\section{Identification of Suitable Indicators}

After identifying the range of indicators used now, the indicators needed to monitor the water-related SDGs were identified and a set of more suitable indicators were then used to develop the NBF, following a similar approach to that used for the CBF (Koop and Van Leeuwen 2015a, b). The NBF developed is designed to provide a national level of water management monitoring toward the goals for Agenda 2030 and therefore the indicators used include those for the SDGs, but also complementary indicators. For each of the indicators specific targets were chosen, taken from those already present for the SDGs or a current EU target (European Commission 2017a). For those indicators for which no numerical target was available, a reasonable goal, based on scientific literature is proposed. The research process is shown in Fig. 2.

\section{Indicator Requirements}

At present, some of the SDG 6 indicators have not been defined in a SMART manner. To ensure goals are clear and reachable, indicators should be SMART. Furthermore, indicators need to be simple so that they are useable and communicable to a range of practitioners, from industry, municipalities, governments, and Nongovernmental organizations (Table 2).

The indicators are chosen based on the measurement endpoints and practical limitations such as data availability.
Table 2 Requirements for indicators (European Commission 2017b; Koop and Van Leeuwen 2015a)
Easy to access

Easy to understand

Timely and relevant

Reliable and consistent

Credible, transparent, and accurate

Developed with the end user in mind
Specific (simple, sensible, significant). Measurable (meaningful, motivating). Achievable (agreed, attainable). Relevant (reasonable, realistic and resourced, results-based).

Time bound (time-based, time limited, time/cost limited, timely, time-sensitive).
To determine whether water professionals would find the selected indicators useful, the proposed indicators were launched at the AIWW Summit in 2018. This resulted in some alternative suggested indicators, as well as the suggested progress-based approach. From this, the final set of indicators and their calculation methods was defined.

The main bottleneck in the development of indicators is to find reliable input (data) to calculate the indicator scores. In this study the focus has been on countries of the EU. This means that different specific sources of information can be used, e.g., data from Eurostat, data from the European Environmental Agency, and data from the OECD. For nonOECD countries, data are generally scarce and indicator development and calculations may be hindered or not be possible at all.

\section{Indicator calculation}

The selected data for the indicators was available as both continuous values and pre-calculated numerical values. To be 
able to reach a final indicator value, two calculation steps had to be carried out. The first is to calculate the distance from the nation's current raw data value to the target value. This gives a value for the progression toward the target. Following this, the progression value is then converted to a value between 0 and 10 to give the final indicator value. The value of 10 indicates that the target has been reached. Once the total number of indicators for a country had been collected, the geometric mean is calculated to find the National Blueprint Index (NBI) of the 24 indicators of the NBF. The geometric mean (Eq. 1) is used in preference to the arithmetic mean as it emphasizes the need to improve the lowest scoring indicators. The addition of plus one to each indicator score means that indicators with a zero value do not result in an index score of zero. This approach is similar to the City Blueprint Approach as developed by Koop and Van Leeuwen (2015a, b).

$$
\mathrm{NBI}=\sqrt[n]{\left(a_{1}+1\right) \times\left(a_{2}+1\right) \ldots\left(a_{n}+1\right)}-1
$$

\section{Framework Analysis}

Once the data had been collected the results were analyzed to determine if there were any dependencies between the indicators and whether the resultant scores made sense. The CBF was used to check the scores as it was assumed, given that the NBF was developed in a similar way, that there would be a linearity between the results. To be able to assess the dependencies between the indicators an internal indicator cross correlation was carried out. For this each indicator was measured against every other indicator and correlations compared. The assessment of the scores and the applicability of the indicator was done by selecting the identical CBF and NBF indicators for the countries that overlapped also using the Pearson's rank correlation coefficient. In this analysis, both the correlation of country level results and the correlation between two similar indicators was carried out. The country level results were assessed to see if the end result showed a similar pattern to those seen at a city level. The correlation analysis used the Pearson calculation as it is applicable for this calculation because the dataset is linear and normally distributed.

\section{Results}

\section{Indexes for Water Management}

The review of IWRM frameworks revealed that the current IWRM indicators follow a diverse methodological approach. Some require data made available at a national level, others depend on gathering data via questionnaires. The indicators can measure the preventative steps in place, such as good governance and management frameworks, or
Table 3 The Indicator frameworks included in the indicator database

\begin{tabular}{ll}
\hline Indicator frameworks & Source \\
\hline $\begin{array}{l}\text { National Water } \\
\text { Management Index }\end{array}$ & Asian Development Bank (2016) \\
$\begin{array}{l}\text { City Blueprint Framework } \\
\text { Canadian Water }\end{array}$ & $\begin{array}{l}\text { Koop and Van Leeuwen (2015a, b) } \\
\text { Gustainability Index }\end{array}$ \\
$\begin{array}{l}\text { City Resilience Index } \\
\text { Environmental }\end{array}$ & $\begin{array}{l}\text { Arup (2014) } \\
\text { Performance Index }\end{array}$ \\
Global water security Index & Wendling et al. (2018) \\
Sustainable City Water Index & Gain et al. (2016) \\
SWESES & Batten (2016) \\
TWAP-rivers & Kilkıs (2018) \\
\hline
\end{tabular}

investment in infrastructure like in the CBF (Koop and Van Leeuwen 2015a, b) and by the Asian Development Bank (2016). Indicators can also measure the current situation level, such as the age of sewer, or the problem such as the amount of water leakage.

Of the total IWRM frameworks identified in the literature review, nine were selected (Table 3 ) as the most relevant for further exploration into the indicators used. This yielded a database of 186 indicators that are currently used for IWRM. From the total of 186 indicators, only $13 \%$ of these were used more than five times. The most common indicators included access to water, access to sanitation, drinking water quality, and the level of secondary wastewater treatment (WWT). Whilst indicators assessed were predominantly performance related indicators, which measure the current state, the approach of the IWRM Indices depends on what they wish to achieve. For example, the Sustainable City Water Index has indicators for water balance and water reserves (Batten 2016) as this is monitoring how well a city manages water in a sustainable manner to not over consume resources. Conversely, the TWAP Index does not contain these indicators but has indicators such as political tension and legal frameworks within the river basin. This is due to the indicator measuring the impact of the water course being a transboundary resource and therefore includes the risk of potential resource conflicts. Both the TWAP Index and the Sustainable City Water Index contain an indicator for Water Stress as this relates both to sustainability and the potential for conflicts.

When the IWRM indicators were compared with the indicators used for SDG 6, there was very little overlap with only $28 \%$ of the indicators in the IWRM indices also being used for SDG 6. The indicator for the degree of IWRM implementation (SDG 6.5.1) was not measured at all. However, the indices did contain indicators such as "management and action plans" or "effective management" 
which are less specific indicators of resource management. The lack of this indicator may be due to the indicator frameworks being used as part of an IWRM management plan, for example the Canadian Water Sustainability Index, and therefore it was not relevant to include IWRM implementation as an indicator.

Change in water-use efficiency, water stress, and the transboundary water cooperation agreement indicator (indicators 6.4.1, 6.4.2 and 6.5.2 respectively) were also lacking from many of the indices and each only occurred twice. The reason for the lack of inclusion may be due to multiple different facts such as lack of data availability, aggregation of data and a lack of perceived value. The efficiency of water use requires data to be gather over a number of years, which may have only recently begun. The transboundary management may have been included within the other management indicators and not disaggregated into a separate indicator.

\section{Alignment of the SDGs with Current IWRM Indicators}

Each IWRM Index is designed for a different setting, some having a river basin as the unit of analysis, some others a more urban or regional setting. IWRM can also be designed for disaster prone or less developed areas having indicators specific for that level of development. However, there are some indicators that are deemed to be important in multiple locations. These indicators also align with those required for SDG indicator monitoring. Of the 138 IWRM indicators assessed, only 38 were indicators that were also used in the SDGs. Of these, $78 \%$ included access to water within their index, however, the only disaggregation of this indicator is between the access to drinking water and the drinking water quality. The second most common indicators present in $67 \%$ of Indexes were access to adequate sanitation and proportion of wastewater safely treated. For most of the indexes, this included any wastewater treated with secondary or higher level of WWT. Only the CBF (Koop and Van Leeuwen 2015a) included further disaggregation. The presence of good ambient water quality was measured in the indexes by the groundwater quality. However, water quality, measured in the environment was an uncommon indicator and only occurred in $33 \%$ of indexes. The SDG indicators that were least represented were change in water efficiency over time and level of water stress. These were present in only $22 \%$ of the indexes. Figure 3 shows that there are some significant gaps in the SDG indicators that are also found in IWRM indexes. This highlights a lack of available data for the specific SDG indicators, rather than that they are deemed unimportant as, other indicators are used that still align with the SDG targets.

In total 66 indicators correlated with the SDG targets compared with only 38 indicators that correlated with the

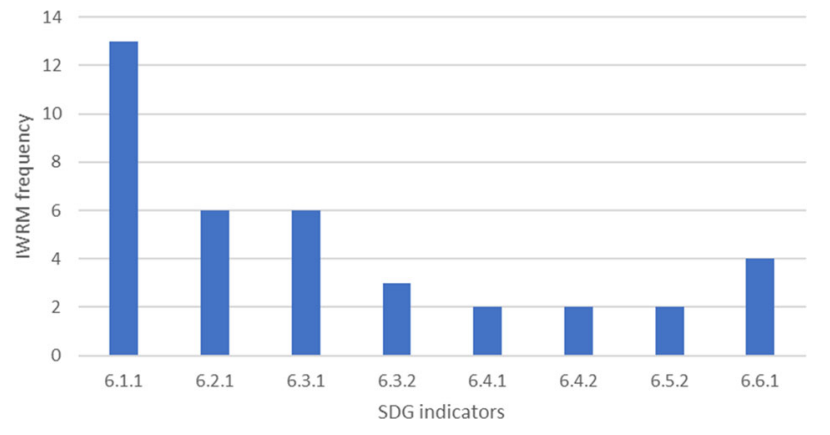

Fig. 3 Number of IWRM indicators that align with the SDG indicators

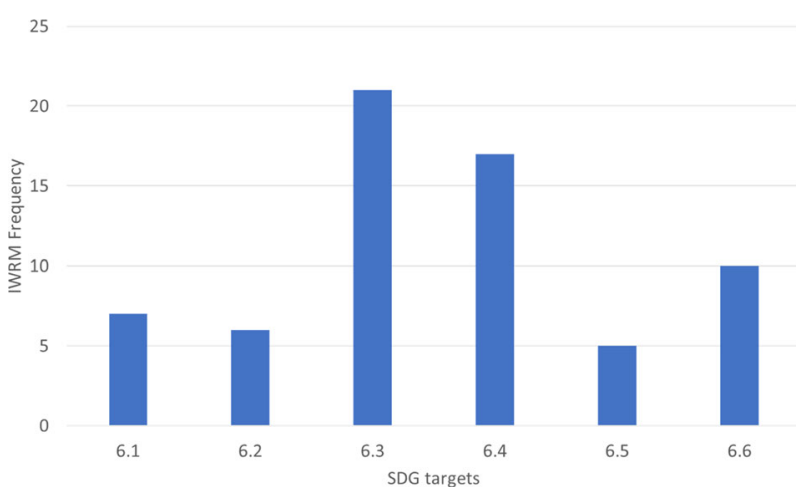

Fig. 4 Number of IWRM indicators that align with the SDG targets

SDG indicators. A high number of indicators are relevant to SDG targets 6.3 and $6.4,15 \%$ and $12.5 \%$, respectively, but the specific SDG indicators are not commonly used. There is a smaller range of indicators that align with targets 6.1, 6.2, and 6.5 (Fig. 4). Of the total number of indicators that aligned with the SDG targets only $10 \%$ aligned with target $6.1,9 \%$ with 6.2 , and $8 \%$ for target 6.5 . The indicators that aligned with 6.1 and 6.2 were identical for all indexes and were used by $78 \%$ and $68 \%$ of indexes respectively. This suggests that there is a high amount of data availability for the desired indicator and that there is cohesive thought in what indicator is needed. The lowest number of target and indicator synergies was seen with target 6.5. From the total number of indicators assessed, only $4 \%$ correlated with desired outcomes from target 6.5. The indicator only occurred in $44 \%$ of the total number of indexes assessed, and in one index, an indicator that aligned with target 5 occurred twice. This may be due to a lack of data or that water management is not perceived as an ideal IWRM monitoring measurement.

There is limited alignment between the SDG indicators and targets and the indicators produced for IWRM. This is in part because there are only 11 indicators for SDG 6, whereas all of the IWRM indicators assessed had greater than 15 indicators. The fact that only $28 \%$ of indicators align with the SDG indicators is in part due to their being 
more indicators per index initially. This is supported by the increased alignment of IWRM indicators with the SDG targets at $49 \%$ of indicators aligning. Where there is a lack of indicator alignment, an increase in target alignment is seen. This suggests that where there is a lack of available data the water management professionals find varying indicator alternatives for the same area of water management. This indicates that the themes seen as being required to monitor water management are cohesive between water professionals and those who designed the SDGs.

\section{Indicator Development, Selection, and Application}

\section{The selection of indicators}

SDG 6 has only 11 indicators (Table 1), suggesting that there are many areas where complimentary water indicators would provide further information on the progression toward healthy water and sanitation. The IWRM indicators were used to provide a set of possible indicators for each target. From this an "ideal" set of indicators was selected according to the best options for measurement end goals. Data availability limited the use of some of these indicators and therefore a second set of feasible indicators was created for which data is available. The limitations in data availability were primarily in monitoring water efficiency and climate mitigation measures. A reliable data source was also necessary, the most readily available indicators were those collected by the UN due to its global coverage and reliability. There was a lack of data for water quality and water infrastructure management. Other indicators that were lacking or difficult to source include those for progression toward a circular economy. In some cases, calculation from the available data can provide a proxy indicator for this measurement. Once completed, this set of feasible indicators was sent for review by water professionals to check their opinion on the indicators relevance and meaningfulness. The indicators suggested by the review team (see "Acknowledgements") included ecological water quality being separated from the surface water quality indicator as well as the inclusion of an indicator for water affordability. The final set of NBF indicators, divided into seven categories, is shown in Table 3.

To be able to show progression of each of the indicator it is required to have a specific target. Many targets and goals developed for agenda 2030 are not numerical. Targets 6.1 and 6.2 include the phase "access for all", which has been assumed to mean $100 \%$ coverage. Target 6.3 aims to "improve water quality" without a numerical target given and target 6.4 aims to "substantially increase water-use efficiency". Whilst this means that countries with different levels of development can all aim to achieve the targets, it does not provide a goal to aim for. For indicators with no clear goal, the next step was to check European targets. Only $16 \%$ or the indicators have useable SDG targets, compared with $38 \%$ of the indicators for which there was an EU target. The remaining indicators have targets supported by the literature. Table 4 summarizes the targets chosen for each NBF indicator.

\section{Linking the selected indicators with the SDGs}

Each of the indicators aligns with a specific target, some of the indicators are developed from the SDG indicators for which there is data available. The remaining indicators are complementary. The alignment of the indicators with the SDG targets can be seen in Table 5.

\section{Results for the EU-28}

Details of the calculation of all indicators and the NBF spider diagrams for the EU-28 are provided in Supplementary Material. The results for the indicator scores of three EU countries is shown in Fig. 5. For the framework to be useable, it needs to clearly show the differences between the EU countries assessed. To check this the standard deviation of the results was calculated and shown in Fig. 6. The indicator showing the highest variability among the EU-28 is SW generated. The score with the least variability is the Notre Dame Readiness Index. This may be due to the global scale of the Notre Dame Readiness Index compared with the SW generated. An example of an indicator with a high variation between the EU-28 is tertiary WWT (Fig. 7). This provides great opportunities for strengthening international collaboration on IWRM between the EU-28, i.e., country-to-country learning. Other indicators that show low variability include the connection to drinking water supply and drinking water quality. There is an overall high score for drinking water and sanitation connections, however, in some countries with generally lower scores, there is a trend for sanitation to score lower than drinking water connection. It can also be concluded that more progress is needed toward energy and nutrient recovery to meet the circular economy ambitions in Europe (Van Leeuwen et al. 2018; Van Puijenbroek et al. 2019). The lowest overall NBI score was for Malta, and the highest overall NBI was for Finland. Malta also has the largest deviation in the indicator results, whereas France has the most consistent scoring (see Supplementary Material).

\section{Discussion}

\section{Development of the NBF}

The NBF is a proposal for a set of progress-based indicators that can help the countries in achieving the SDGs. The 


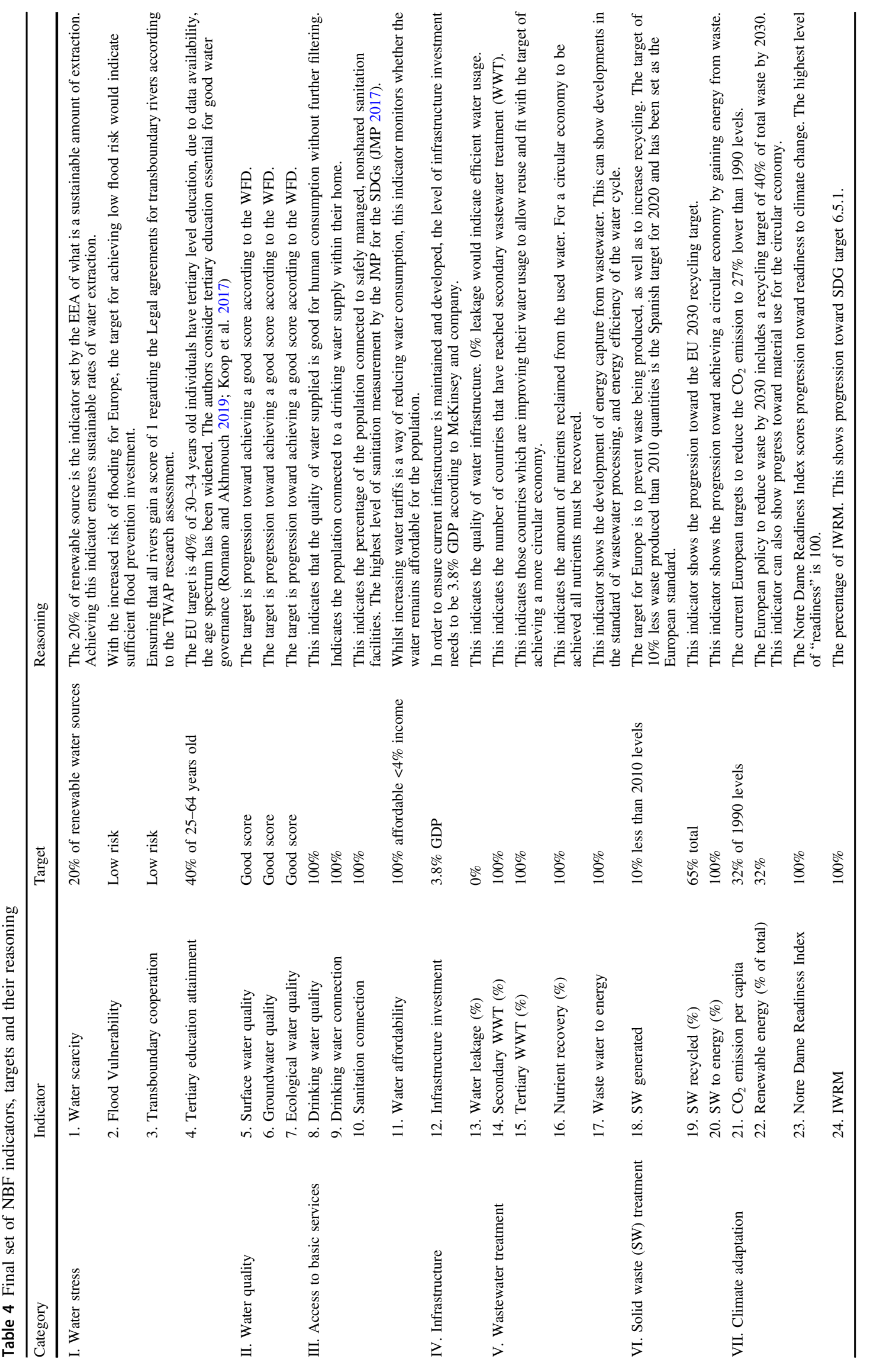


Table 5 SDG 6 and links between the key NBF indicators and complementary indicators and goal targets

\begin{tabular}{|c|c|c|c|}
\hline NBF indicators & SDG direct goal link & Indirect SDG 6 link & SDG goal interlinkages \\
\hline 1. Water scarcity & 6.4 .2 & & $16,8,2$ \\
\hline 2. Flood vulnerability & & & 15,13 \\
\hline 3. Transboundary cooperation & & 6.5 .2 & 17 \\
\hline 4. Tertiary education attainment & & & 4,9 \\
\hline 5. Surface water quality & 6.3 .2 & & 15,3 \\
\hline 6. Groundwater quality & 6.3 .2 & & 15 \\
\hline 7. Ecological water quality & 6.3 .2 & & 3,15 \\
\hline 8. Drinking water quality & 6.1 .1 & & 3,2 \\
\hline 9. Drinking water connection & & 6.1 & $3,15,5,4$ \\
\hline 10. Sanitation connection & & & 3,5 \\
\hline 11. Water affordability & & & 1,10 \\
\hline 12. Infrastructure investment & & 6.2 & 9 \\
\hline 13. Water leakage $(\%)$ & & 6.4 & $9,11,12$ \\
\hline 14. Secondary WWT (\%) & 6.3 .1 & & 3,11 \\
\hline 15. Tertiary WWT (\%) & & 6.3 & 3,11 \\
\hline 16. Nutrient recovery $(\%)$ & & & 11,12 \\
\hline 17. Waste water to energy & & & 7,11 \\
\hline 18. SW generated & & & 11 \\
\hline 19. SW recycled $(\%)$ & 12.5 & & $11,13,12$ \\
\hline 20. SW to energy $(\%)$ & & & $7,11,12$ \\
\hline 21. CO2 emission per capita & & & 13 \\
\hline 22. Renewable energy $\%$ total & & & $7,11,13$ \\
\hline 23. Notre Dame Readiness Index & & & 13 \\
\hline 24. IWRM & 6.5 .1 & & 17,12 \\
\hline
\end{tabular}

indicators chosen stem from current IWRM indicators, including those for the SDGs. The set of proposed waterrelated indicators of the NBF reaches a total of 24 indicators that are grouped into seven categories as shown in Table 4. The aim of the NBF is to use SDG 6 targets and indicators and to provide complementary indicators relevant for the water sector. We collected information for the EU-28 to demonstrate their implementation.

The popularity of indicators for policy implementation has led to an extensive use of indicators for a wide range of contexts (see Table 3). The initial search showed that indicators frameworks had been previously reviewed, in terms of their applicability for sustainable cities (European Commission 2015; Hoekstra et al. 2018) as well as their for usability as a sustainability indicator (Pires et al. 2017). However, there was a lack of information of frameworks applied at a national level and neither of the reviews focused on the use of the indicator frameworks in achieving the SDGs. To develop an overview of national level IWRM frameworks, a separate review was therefore carried out.

Due to the volume of indicators available and the time constraints of the project only nine IWRM frameworks were fully reviewed. These indicators contained 186 indicators, but only $35 \%$ were relevant to the SDGs. The review of the indexes was not limited by the perspective or the goal of the index. For instance, the TWAP reviewed the water management with a focus on issues which would cause conflict to transboundary water sources, such as water stress and poor governance. Conversely many of the other indexes had a far more introspective focus on national or city-based issues such as community involvement and performance of service utilities. When the IWRM indicators were compared against the SDG indicators it became apparent that indicators that had been used within the MDGs, such as Access to improved drinking water (MDG 7) were more popular than those not included such as water efficiency (SDG 6.4.1) and water management (SDG 6.5.1). For those already collected as part of the MDGs, it is likely that there is already easily accessible data available for these indicators and hence the wide usage of specific indicators.

\section{Strength and Weaknesses of the SDGs}

The SDGs are an important step toward sustainability, resilience, and social security. Many of the SDGs are waterrelated (Fig. 1), but they are currently difficult to implement, mainly because the targets and indicators (Table 1) 
Fig. 5 Indicator scores for the NBF for Finland (top), Italy (middle), and Malta (bottom) they receive an NBI score of 5.8, 4.5 , and 2.6 , respectively
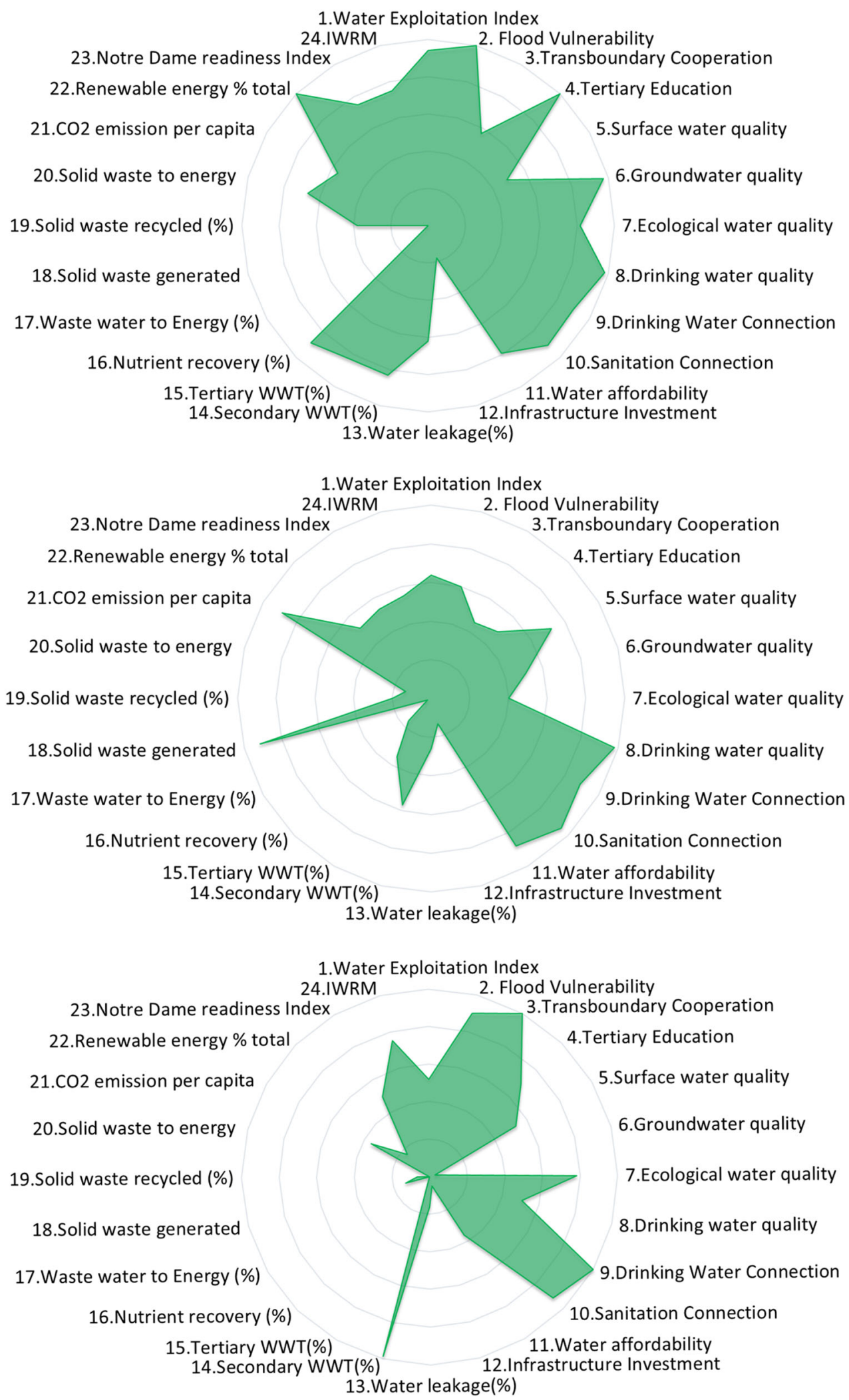

1.Water Exploitation Index 24.IWRM 2. Flood Vulnerability

23. Notre Dame readiness Index 2.Renewable energy \% total

21.CO2 emission per capita

20.Solid waste to energy

19.Solid waste recycled (\%)

18.Solid waste generated

17.Waste water to Energy (\%)

16.Nutrient recovery (\%)

5.Tertiary WWT(\%)

13.Water leakage(\%)

1.Water Exploitation Index

3.Transboundary Cooperation

4.Tertiary Education

Surface water quality

7.Ecological water quality

8.Drinking water quality

9.Drinking Water Connection

10.Sanitation Connection

.



28
Fig. 6 Standard deviation of indicator results among the EU-

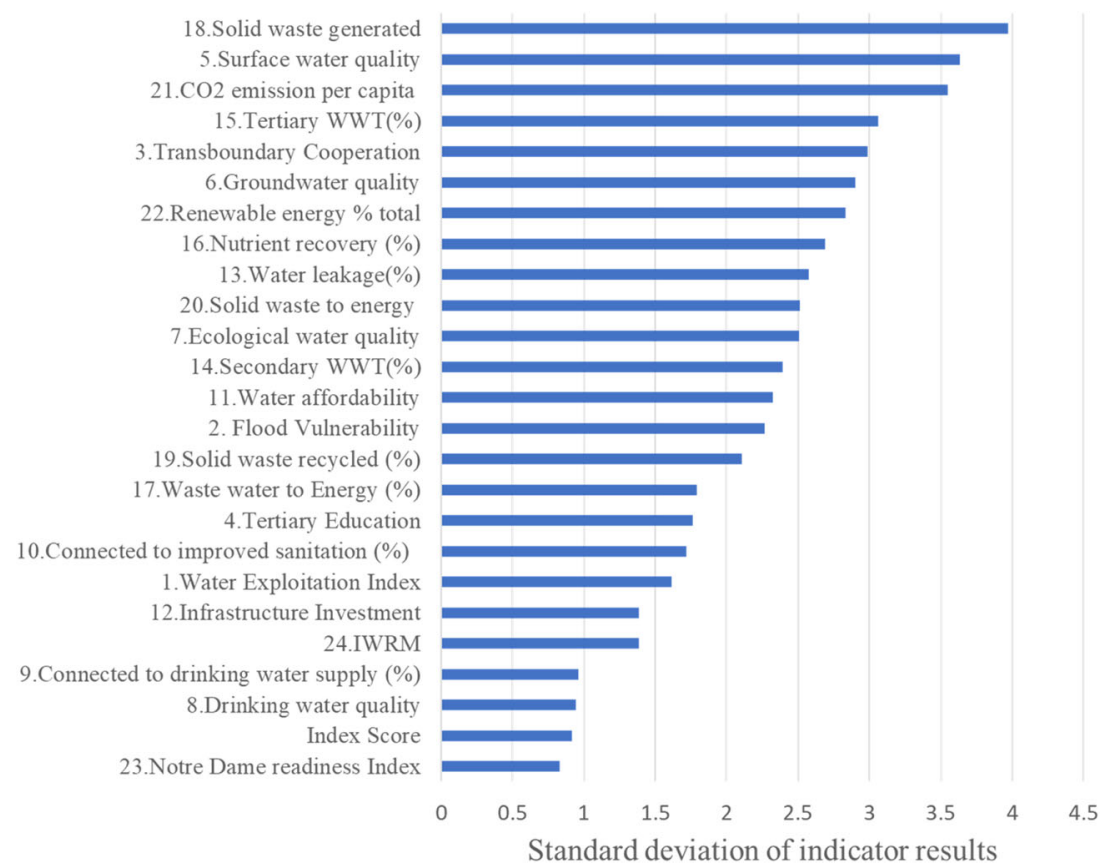

Fig. 7 Comparison of tertiary wastewater treatment (\%) among the EU-28

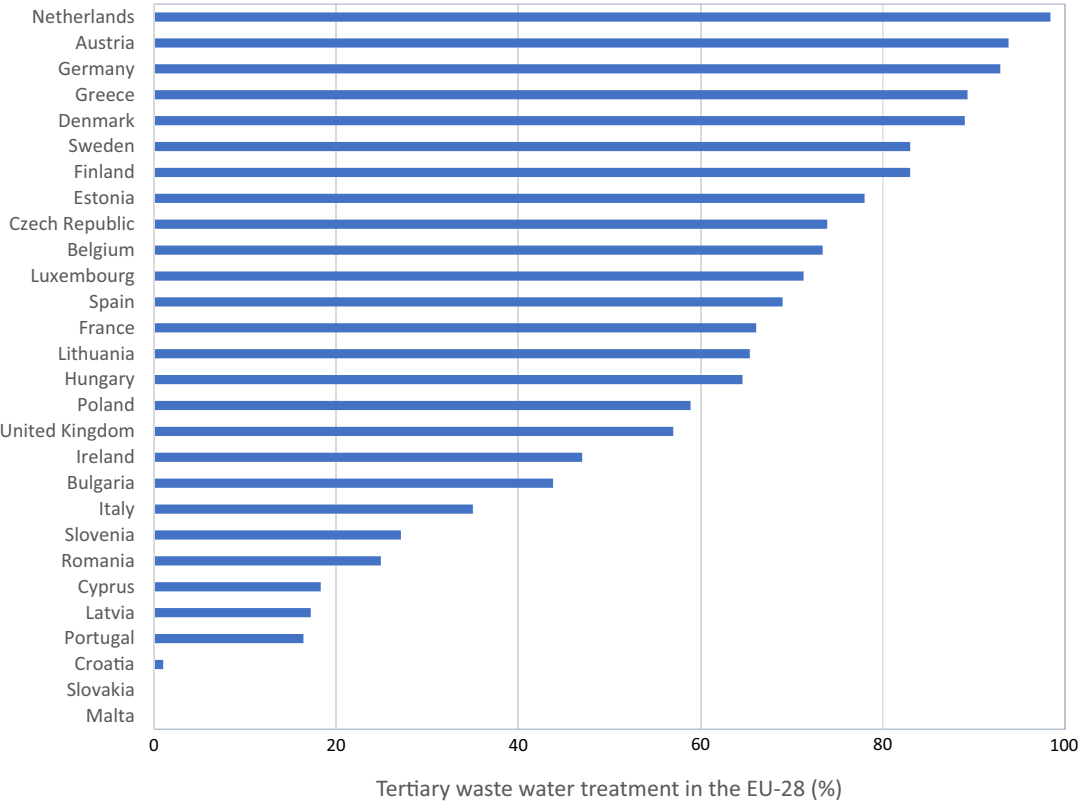

into account safe collection, treatment and disposal of wastewater and fecal sludge, vital to disease prevention. The absence of clear targets are hindering effective implementation. The inclusion of targets for the indicators allows the measurement of progress toward a goal rather than the current performance of the nation. Showing progress toward a goal increases the use of the indicator as policy makers can discern whether they are on track to meet a target. Whilst the SDGs have 169 targets, very few of these have precise numerical goals. For those targets that did have numerical goals, these were chosen as the end target. The
Sustainable Development Scenarios discussed at the Rio +20 United Nations Conference on Sustainable Development (United Nations Department of Economic and Social Affairs 2013) equally do not have many specific numerical targets for water and those that do, such as the target to give another 230 million people access to an improved water source is a target on a global rather than national scale and therefore difficult to apply nationally as the target is not relevant to every nation. The conclusion is that next steps are needed to improve the SDGs. The selection of waterrelated indicators and targets as proposed in this manuscript 
should be considered only as an example. It shows that it is possible to improve the SDGs, to better implement them, and that this is doable. We fully realize that other scientists may have arrived at another set of indicators. Anyhow, it is not up to scientists to decide on which indicator and targets should be selected but to the science-policy arena.

\section{Data Availability}

The proposed NBF was also applied to some non-EU countries (South Korea, USA, Tanzania and Brazil) to test its global relevance. The largest problem found in applying the NBF was the lack of data. In total, data for 16 indicators could be found for South Korea and the United States, with only 13 indicators having the required data for Tanzania, this number decreased to only 12 for Brazil. The larger number of indicators found for South Korea and Brazil was due to them being part of the OECD and therefore present in those datasets. In some cases, alternative proxy indicators were used, such as for water access to drinking water, the EU countries used "proportion of the population using improved water supplies" which were under the category of 'safely managed' from the World Health organization. However, for South Korea, Brazil, and Tanzania, there was no data available for 'safely managed' and instead, "piped" category was used instead. In other instances, the data was not available from the source used for the EU and was instead found from other data sources. To compare index scores of the non-EU countries, the indicators for which every country had data were separated. From the indicator scores, the geometric mean was calculated to create an index for every country. The Index scores were then ranked from 1 (being highest) to 32 (being lowest). South Korea ranked 28th but the United States, Brazil, and Tanzania ranked 30th, 31st, and 32nd, respectively.

The points above suggest that more data needs to be collected and made readily available for global datasets and what gets measured will get managed (Georgeson and Maslin 2018), it is important that to achieve the SDGs for water, good governance needs to occur and so also data collection for the indicators. However, excess collection may put undue pressure on the nation and take resources away from other areas of management (Dickens et al. 2019).

\section{Problem of Scale and Perspective}

The SDGs are designed to be implemented on a global scale and as such, the indicators need to be applicable to every country. This is highlighted in indicators such as SDG 6.1.1 Proportion of population using safely managed drinking water services and 6.2.1 Proportion of population using safely managed sanitation services, including a hand- washing facility with soap and water. In the EU, these average at $91 \%$ and $80 \%$ achievement, respectively. Whilst there is still room for improvement, these indicators do not help to determine the cause for the lack of these services or the degree to which these services are efficient and sustainable. If it did, those countries scoring highly could identify where there is still room for improvement. This leads to the problem of not every country having the same starting point (Equal Measures 2030 2019) with the global south having more progress required in social indicators, whereas the global north has a greater focus on achieving the environmental indicators.

The framework was developed from the SDGs but also a set of indicators that primarily were sourced from initiatives in the global north, which leads to a bias within the framework of indicators relevant to the state of development within the EU. The impact of this on the developed framework can be seen when it is applied to the non-EU countries, where Tanzania scores 10 for renewable energy $\%$ (NBF indicator 22) but only 3.5 for Connected to drinking water supply (NBF indicator 9). Some of the indicators are related to the circular economy of water and measured in a way that works with European infrastructure, this assumes a European model of development. As well as the indicators being relevant to Europe, the targets too are based on the EU goals, and targets that could be realized in this situation. However, as not all countries have the same starting point, it would not be realistic to assume they could achieve the same end goal in 15 years.

The variation in the NBI for the EU-28 is small. The NBI varied from 2.6 (Malta) to 5.8 (Finland) as shown in Fig. 5. The BCI allows a comparison of the municipalities and regions per country (Gawlik et al. 2017). The differences in the BCI among the municipalities is relatively small. In this regard the NBF may be indicative for a country to monitor progress toward SDG 6, but often, solutions have to be created at the level of regions and municipalities, where most of us live (Koop and Van Leeuwen 2017). For instance, for ten municipalities assessed in the Netherlands the BCI varied from 5.7 to 8.3. For the UK, with five municipalities and regions assessed, the BCI varied from 5.3 to 6.7. For Sweden with five municipalities assessed the BCI ranged from 6.9 to 7.8. For the USA, with six cities assessed, the BCI ranged from 3.9 to 5.4 (Feingold et al. 2018).

Based on the research carried out, we propose an NBF with 24 water-related indicators centered on SDG 6, with complementary indicators (e.g., to monitor goals related to the circular economy of water) including quantitative policy targets. The NBF indicators are complementary to the CBF indicators to measure water management performance at municipal and/or regional level. This is where probably most of the efforts are needed. 
We realize that in the end the selection of indicators and their quantitative targets are political decisions. We also realize that the collection of data can be a burden for many nonOECD countries, but informed decision-making and exploring synergies or co-benefits is the way forward (Koop and Van Leeuwen 2017). If "what gets measured gets managed, measuring the wrong thing" or neglecting to measure at all, really matters (Barnett 2015; Georgeson and Maslin 2018). In our view it is better (and certainly cheaper) to do an in-depth diagnosis on SDG 6, than to implement regrettable transitions (UNEP 2013) to modernize and expand the world's urban water infrastructure as the projections of global financing needs for water infrastructure range from USD 6.7 trillion by 2030 to USD 22.6 trillion by 2050 (OECD 2019b). Looking at the crucial role of water in the SDG framework (Fig. 1), quoting former Prime Minister Wim Kok of the Netherlands is quite appropriate here as he once said: "a priority is only a priority if you give it priority".

\section{Conclusions}

(1) The current SDG 6 indicators are useful for monitoring progress toward water-related targets but their usefulness can be improved significantly by focusing more on their practical implementation.

(2) The extension of SDG 6 with complementary indicators (e.g. to monitor goals related to the circular economy of water) and quantitative policy targets is urgently needed. This will benefit the communication process of monitoring SDG 6 progress at the sciencepolicy interface.

(3) The implementation of the ambitious SDGs can be improved by reformulating the indicators in a SMART manner and by setting clear policy targets for each of the indicators, allowing for measuring distance-to-targets. In this way international country comparisons can be made.

(4) We propose 24 water-related indicators centered on SDG 6, with complementary indicators including quantitative policy targets. We realize that in the end indicators and quantitative targets are political decisions.

(5) We demonstrate that this approach is doable, easily scalable, and flexibly deployable by collecting information for the EU-28.

(6) Main gaps at national level in the EU-28 are observed for water quality, WWT, nutrient, and energy recovery, as well as for climate adaptation to extreme weather events, e.g. extreme heat, droughts, and floods. This provides options for further international collaboration or country-to-country learning to speed up the SDG implementation process.
(7) Whilst the NBF scores for the EU-28 correlate with municipal and regional water management performance, the framework was less successful for non-OECD countries due to the restricted data availability and EU-centric targets for each indicator. This needs further research.

Acknowledgements This study has been commissioned by the Amsterdam International Water Week (AIWW 2019) and Waternet (Amsterdam, the Netherlands) to show the current progress and challenges in water related SDGs at a national level in Europe. The identified challenges can provide direction to the focus and themes of AIWW in 2019-2030. The approach described in this report has been presented and discussed in three round tables at the AIWW Summit 2018 (15 November, Rotterdam) as well as with the AIWW Advisory Committee (12 February and 1 October 2019 at Waternet, Amsterdam). Results from the first review by the AIWW Advisory Committee have been incorporated in the final report, and the results of the study will be presented at AIWW 2019. We acknowledge the input of Carel Dieperink (Copernicus Institute for Sustainable Development, Utrecht University, NL), the AIWW advisory committee: Roelof Kruize (chair \& CEO Waternet, member Managing Board AIWW); Bianca Nijhof (CEO NWP and coordinator of SDG 6 for the Netherlands), Corinne Trommsdorff (Program Manager Cities of the Future, International Water Association); Dean Muruven (Global Policy Manager Fresh Water at World Wildlife Fund, NL); Gaetano Casale (International relations, Water Europe, Manager liaison office, IHE Delft Institute for Water Education, NL); Hermanus Rietveld (Coordinator Sustainable Development Goals at Statistics Netherlands, the Hague, NL); Hugo von Meijenfeldt (SDG Coordinator, Dutch Ministry of Foreign Affairs, the Hague, NL); Veronica Manfredi (Director for Quality of Life European Commission, Brussels Belgium), Pavel Misiga (head of unit, European Commission, Brussels, Belgium); Jos Frijns (Team leader Resilience Management \& Governance at KWR Water Research Institute, Nieuwegein, NL), Kees van der Lugt (secretary managing board \& program director AIWW 2019, Amsterdam, NL) and Andre Struker (Member Program Team AIWW 2019, Strategic Advisor at Waternet, Amsterdam, NL).

\section{Compliance with Ethical Standards}

Conflict of interest The authors declare that they have no conflict of interest.

Publisher's note Springer Nature remains neutral with regard to jurisdictional claims in published maps and institutional affiliations.

Open Access This article is distributed under the terms of the Creative Commons Attribution 4.0 International License (http://crea tivecommons.org/licenses/by/4.0/), which permits unrestricted use, distribution, and reproduction in any medium, provided you give appropriate credit to the original author(s) and the source, provide a link to the Creative Commons license, and indicate if changes were made.

\section{References}

Allen C, Metternicht G, Wiedmann T (2018) View project Initial progress in implementing the Sustainable Development Goals (SDGs) — a review of evidence from countries. https://doi.org/10. 1007/s11625-018-0572-3 
Arup (2014) City Resilience Index. https://www.arup.com/ perspectives/city-resilience-index. Accessed 14 May 2019

Asian Development Bank (2016) Asian water development strengthening water security in Asia and the Pacific. www.adb.org. Accessed 15 May 2019

Barnett P (2015) If what gets measured gets managed, measuring the wrong thing matters. http://www.strategicmanagementforum.org. Accessed 12 Dec 2018

Batten J (2016) Sustainable cities water index. Arcardis. https://www. arcadis.com/en/global/our-perspectives/which-cities-are-best-pla ced-to-harness-water-for-future-success-/. Accessed 6 Aug 2019

Bhaduri A, Bogardi J, Siddiqi A, Voigt H, Vörösmarty C, Pahl-Wostl C, Osuna VR (2016) Achieving sustainable development goals from a water perspective. Front Environ Sci 4:64. https://doi.org/ 10.3389/fenvs.2016.00064

Brundtland GH (1987) Our common future: report of the world commission on environment and development. U. N. Commun 4 (1):300. https://doi.org/10.1080/07488008808408783

De Graaf IEM, Gleeson T, Van Beek LPH, Sutanudjaja EH, Bierkens MFP (2019) Environmental flow limits to global groundwater pumping. Nature 574:90-94

De Vries BJM (2012) Sustainability science. CUP, Cambridge. https:// doi.org/10.1017/CBO9780511794469

Dickens C, Smakhtin V, McCartney M, O'Brien G, Dahir L (2019) Defining and quantifying national-level targets, indicators and benchmarks for management of natural resources to achieve the sustainable development goals. Sustainability 11(2):462. https:// doi.org/10.3390/su11020462

EEA (2018) Water use by sectors-European Environment Agency. https://www.eea.europa.eu/themes/water/water-resources/wateruse-by-sectors. Accessed 28 Aug 2018

Equal Measures 2030 (2019) Harnessing the power of data for gender equality introducing the 2019 EM2030 SDG Gender Index. https://data.em2030.org/wp-content/uploads/2019/05/EM2030_ 2019_Global_Report_ENG.pdf

European Comission (2015) Science for environment policy: indicators for sustainable cities (12). https://doi.org/10.2779/61700

European Commission (2017a) Europe 2020 Targets. https://ec. europa.eu/eurostat/documents/4411192/4411431/Europe_2020_ Targets.pdf. Accessed 29 Mar 2019

European Commission (2017b) Indicators to measure social protection performance. https://doi.org/10.2841/158380. Accessed $1 \mathrm{Apr}$ 2019

FAO (2016) AQUASTAT MainDatabase, Food and Agriculture Organization of the United Nations. http://www.fao.org/nr/wa ter/aquastat/data/query/index.html?lang=en. Accessed 2 Oct

FAO (2018) More people, more food, worse water? A global review of water pollution from agriculture. Food and Agriculture Organization of the United Nations, Rome, Italy. http://www.fao.org/3/ CA0146EN/ca0146en.pdf

Feingold D, Koop S, Van Leeuwen K (2018) The city blueprint approach: urban water management and governance in cities in the US. Environ Manag 2018(61):9-23

Gain AK, Giupponi C, Wada Y (2016) Measuring global water security towards sustainable development goals. Environ Res Lett 11(12):124015. https://doi.org/10.1088/1748-9326/11/12/124015

Gawlik BM, Easton P, Koop S, Van Leeuwen K, Elelman, R (2017) Urban water atlas for Europe. Publications Office of the European Union. https://publications.europa.eu/en/publication-detail/-/ publication/c296a413-24cc-11e7-b611-01aa75ed71a1

Georgeson L, Maslin M (2018) Putting the United Nations Sustainable Development Goals into practice: a review of implementation, monitoring, and finance. https://doi.org/10.1002/geo2.49

Giordano M, Shah T (2014) From IWRM back to integrated water resources management. Int J Water Resour Dev 30(3):364-376. https://doi.org/10.1080/07900627.2013.851521
Guppy L, Mehta P, Qadir M (2019) Sustainable development goal 6: two gaps in the race for indicators. Sustain Sci 14(2):501-513. https://doi.org/10.1007/s11625-018-0649-z

HLPW (2018) Making Every Drop Count. https://sustaina bledevelopment.un.org/HLPWater

Hoekstra AY (2014) Water for animal products: a blind spot in water policy. Environ Res Lett 9:091003. https://doi.org/10.1088/17489326/9/9/091003

Hoekstra AY, Buurman J, Van Ginkel KCH (2018) Urban water security: a review. Environ Res Lett 13:53002. https://doi.org/10. 1088/1748-9326/aaba52

Hoekstra AY, Mekonnen MM, Chapagain AK, Mathews RE, Richter BD (2012) Global monthly water scarcity: blue water footprints versus blue water availability. PLoS ONE 7(2):e32688. https:// doi.org/10.1371/journal.pone.0032688

Howard G, Bartram J (2003) Domestic water quantity, service level and health. World Health Organisation. https://www.who.int/wa ter_sanitation_health/diseases/WSH03.02.pdf. Accessed 2 Oct 2019

Hunter PR, MacDonald AM, Carter RC (2010) Water supply and health. PLoS Med 7(11):e1000361. https://doi.org/10.1371/ journal.pmed.1000361

JMP (2017) Sanitation. UNICEF, https://washdata.org/monitoring/sa nitation. Accessed 2 Aug 2018

Kılkış Ş (2018) Sustainable development of energy, water and environment systems (SDEWES) index for policy learning in cities. Int J Innov Sustain Dev 12(1-2):87-134

Koop SHA, Koetsier L, Van Doornhof A, Reinstra O, Van Leeuwen CJ, Brouwer S, Dieperink C, Driessen P (2017) Assessing the governance capacity of cities to address challenges of water, waste and climate change. Water Resour Manag 31:3427-3443

Koop SHA, Van Leeuwen CJ (2015a) Assessment of the sustainability of water resources management: a critical review of the city blueprint approach. Water Resour Manag 29(15):5649-5670. https://doi.org/10.1007/s11269-015-1139-z

Koop SHA, Van Leeuwen CJ (2015b) Application of the improved city blueprint framework in 45 municipalities and regions. Water Resour Manag 29(13):4629-4647. https://doi.org/10.1007/ s11269-015-1079-7

Koop SHA, Van Leeuwen CJ (2017) The challenges of water, waste and climate change in cities. Environ Dev Sustain 19:385-418. https://doi.org/10.1007/s10668-016-9760-4

Lambin EF, Meyfroidt P (2011) Global land use change, economic globalization, and the looming land scarcity. Proc Natl Acad Sci USA 108(9):3465-3472. https://doi.org/10.1073/pnas.1100480108

Makarigakis A, Jimenez-Cisneros B (2019) UNESCO's contribution to face global water challenges. Water 11(2):388. https://doi.org/ 10.3390/w11020388

Malik OA, Hsu A, Johnson LA, De Sherbinin A (2015) A global indicator of wastewater treatment to inform the Sustainable Development Goals (SDGs). Environ Sci Policy 48:172-185. https://doi.org/10.1016/J.ENVSCI.2015.01.005

Medema W, McIntosh BS, Jeffrey PJ (2008) From premise to practice: a critical assessment of integrated water resources management and adaptive management approaches in the water sector. Ecol Soc 13(2):art29. https://doi.org/10.5751/ES-02611-130229

Nilsson M, Griggs D, Visbeck M (2016) Map the interactions between Sustainable Development Goals. Proc Natl Acad Sci USA 382:5125-5129. https://doi.org/10.1787/agr_outlook-2015-en

OECD (2017) Measuring distance to SDG targets. http://www.oecd. org/sdd/OECD-Measuring-Distance-to-SDG-Targets.pdf

OECD (2019a) Measuring distance to the SDG targets 2019: an assessment of where OECD countries stand, OECD Publishing, Paris. https://doi.org/10.1787/a8caf3fa-en

OECD (2019b) Making blended finance work for water and sanitation: unlocking commercial finance for SDG 6, OECD studies on 
water, OECD Publishing, Paris. https://doi.org/10.1787/ 5 efc 8950 -en

Petit O (2016) Paradise lost? The difficulties in defining and monitoring Integrated Water Resources Management indicators. Environ Sustain 21(21):58-64. https://doi.org/10.1016/j.cosust. 2016.11.006

Pires A, Morato J, Peixoto H, Botero V, Zuluaga L, Figueroa A (2017) Sustainability assessment of indicators for integrated water resources management. Sci Total Environ 578:139-147. https:// doi.org/10.1016/J.SCITOTENV.2016.10.217

Policy Research Initiative (2007) Canadian Water Sustainability Index (CWSI). Project report. https://doi.org/10.2166/washdev.2012. 005

Pradhan P, Costa L, Rybski D, Lucht W, Kropp JP (2017) A systematic study of sustainable development goal (SDG) earth interact, pp 1169-1179. https://doi.org/10.1002/eft2.266

Rahmasary AN, Robert S, Chang IS, Jing W, Park J, Bluemling B, Koop S, Van Leeuwen K (2019) Overcoming the challenges of water, waste and climate change in Asian cities. Environ Manage, pp 1-16. https://doi.org/10.1007/s00267-019-01137-y

Rasul G (2016) Managing the food, water, and energy nexus for achieving the Sustainable Development Goals in South Asia. Environ Dev 18:14-25. https://doi.org/10.1016/J.ENVDEV. 2015.12.001

Reidhead W, Harlin J, Alabaster G, Slaymaker T, Frenken K, Arduino G, Abrate T (2016) Monitoring water and sanitation in the 2030 agenda for sustainable development-an introduction, pp 1-12. www.unwater.org/app/uploads/.../Monitoring-Water-and-Sanita tion_Introduction.pdf

Robinson J (2004) Squaring the circle? Some thoughts on the idea of sustainable development. Ecol Econ. https://doi.org/10.1016/j. ecolecon.2003.10.017

Romano O, Akhmouch A (2019) Water governance in cities: current trends and future challenges. Water 11:500. https://www.mdpi. com/2073-4441/11/3/500

Savenije HHG, Van der Zaag P (2008) Integrated water resources management: concepts and issues. Phys Chem Earth 33 (5):290-297. https://doi.org/10.1016/J.PCE.2008.02.003

Scherer L, Behrens P, De Koning A, Heijungs R, Sprecher B, Tukker A (2018) Trade-offs between social and environmental Sustainable Development Goals. Environ Sci Policy 90. https://doi.org/ 10.1016/j.envsci.2018.10.002

Siemens AG (2012) The Green City Index. http://etms.espon.eu/ra nkings/2012_European_Green_City_Index_sum_report.pdf
UNEP (2013) In: Swilling M, Robinson B, Marvin S, Hodson M (eds) City-level decoupling: Urban resource flows and the governance of infrastructure transitions. A report of the working group on cities of the International Resource Panel. United Nations Environment Programme. International Resource Panel, Nairobi

UNEP-DHI, UNEP (2016) Transboundary river basins: status and trends. United Nations Environment Programme (UNEP), Nairobi. https://epi.envirocenter.yale.edu/epi-downloads

United Nations (2015a) World population prospects: the 2015 revision. https://esa.un.org/unpd/wpp/Publications/Files/Key_ Findings_WPP_2015.pdf

United Nations (2015b) The millenium development report 2015. https://www.un.org/millenniumgoals/2015_MDG_Report/pdf/ MDG2015 rev(July 1).pdf

United Nations (2015c) Transforming our world: the 2030 agenda for sustainable development. general assembley 70 session, 16301 (October), 1-35. https://doi.org/10.1007/s13398-014-0173-7.2

United Nations (2018) Sustainable Development Goal 6 synthesis report on water and sanitation. https://www.unwater.org/.../sdg-6synthesis-report-2018-on-water-and-sanitation/

United Nations Department of Economic and Social Affairs (2013) Scenarios for sustainable development for Rio +20

UN-Water (2016) Water and sanitation interlinkages across the 2030 agenda for sustainable development. https://www.unwater.org/ publications/water-sanitation-interlinkages-across-2030-agendasustainable-development/

Van Puijenbroek PJTM, Beusen AHW, Bouwman AF (2019) Global nitrogen and phosphorus in urban waste water based on the Shared Socio-economic pathways. Environ Manag 231:446-456. https://doi.org/10.1016/j.jenvman.2018.10.048

Van Leeuwen K, De Vries E, Roest K, Koop S (2018) The energy \& raw materials factory of the Dutch water authorities: its role in the circular economy of the Netherlands. Environ Manag 61 (5):786-795. https://doi.org/10.1007/s00267-018-0995-8

Wendling ZA, Emerson JW, Esty DC, Levy MA, De Sherbinin A, et al. (2018) 2018 Environmental performance index. Yale Center for Environmental Law \& Policy, New Haven, CT. https://epi.ya le.edu/

Weststrate J, Dijkstra G, Eshuis J, Gianoli A, Rusca M (2019) Soc Indic Res 143:795-810. https://doi.org/10.1007/s11205-0181965-5

World Bank (2018) Atlas of sustainable development goals 2018: from world development indicators. World Bank Publication. https:// doi.org/10.1596/978-1-4648-1250-7 